\title{
OPTIMIZATION OF VIBRO-DIAGNOSTIC METHOD FOR MARINE ROTATING PUMPS
}

\author{
Miloš Milovančević, Edvard Tijan, Petra Karanikić
}

Original scientific paper

Techno-economical optimization of vibro-diagnostic method implies defining of the minimal number of vibro-diagnostic information, which could be used for precise and definite diagnosis of broad spectra of failures or malfunctions with all types of rotating machines in standard use, including marine pumps. Economic optimization is done based on competitive advantage approach, but in coherence to technical aspect. Techno-economical optimization in this research is analysed more from the aspect of the optimization problem new formulation than from the aspect of mathematical apparatus for solving the problem. In this case, the optimization is based on establishing the possibility of certain defect appearance at marine rotating machines and implementation of causal relations between diagnostic model and defined goal functions values.

Keywords: diagnostics; optimization; marine rotating pumps; vibrations

Optimizacija vibro-dijagnostičke metode za brodske rotacijske pumpe

Izvorni znastveni članak Tehničko-ekonomska optimizacija vibro-dijagnostičke metode podrazumijeva definiranje minimalnog broja vibro-dijagnostičkih informacija koje se mogu koristiti za precizno i konačno dijagnosticiranje širokog spektra otkaza svih tipova rotacijskih strojeva u standardnoj uporabi, uključujući i brodske pumpe. Ekonomska optimizacija temelji se na pristupu odabira komparativnih prednosti sustava koji ispunjavaju tehničke norme. U ovom istraživanju, tehničko-ekonomska optimizacija se analizira više s aspekta nove formulacije problema optimizacije, nego s matematičkog aspekta za rješavanje problema. U izloženom radu, optimizacija se bazira na utvrđivanju vjerojatnosti pojave određenog otkaza na rotacijskim strojevima i implementacije uzročnih veza između dijagnostičkog modela i definiranih funkcija.

Ključne riječi: brodske rotacijske pumpe; dijagnostika; optimizacija; vibracije

\section{Introduction}

Marine systems are complex and are subject to extensive range of faults. Therefore, the basic requirement that marine systems have to fulfil is reliability. Through the analysis of their reliability it is necessary to observe the reliability of their subsystems and components. Functionality and quality interaction of marine subsystems and components are of essential importance for high efficiency, long operational lifetime and safety. The concept of reliability of marine systems means the probability that the system will successfully perform its function in terms of the environmental conditions and in specific period of time. Reliability is functionally dependent on the failures that can occur in any component of marine systems [1].

Ships which are designed and built to meet the classification rules must have an acceptable level of reliability for safe navigation. Unplanned breakdowns which can occur due to improper maintenance (and which may even render ships inoperable) create financial losses. Every hour of ships' delay produces significant costs. The task of maintenance experts is to make sure that unexpected delays do not occur, or at least to try to reduce the downtime to an acceptable level. In order to increase the operability and safety of navigation, it is necessary to reduce the failure probability of the vital components and systems aboard ships [2]. In technical literature, a great number of papers in the field of technical system maintenance deal with general principles and maintenance approaches. Development of a maintenance plan has proven to be indispensable, in order to enable the crew to perform all urgent maintenance activities within a defined period of time [3].

Rotating pumps are used to transport fluids and are a very important component in various industries. They are often used because of notable characteristics, such as very good efficiency and good flow [4]. Pumps are widely used on-board ships, in engine rooms (seawater cooling, ballast, fuel oil, lube oil, oily bilge, sludge, firefighting) where downtime is definitely not an option, in utility applications (boiler feed, thermal oil, freshwater cooling, sewage, HVAC, water treatment), etc. Pumps are of vital importance in ship exploitation. Pump repair during navigation is not easy or simple, and could be risky for the safety of the crew and the ship. Therefore, it is necessary to provide conditions in which pumps faultlessly perform their functions during the estimated working life, while their replacement and repair are scheduled during docking and regular maintenance of the ship auxiliaries [5].

Pumps have to be reliable, easy to maintain and carry low operating costs, which is even more difficult given the harsh conditions at sea. The ultimate goal should be to effectively reduce the risk of downtime, which will offer peace of mind to both ship owners and engineers. Marinespecific solutions have to ensure that the materials used as well as the reliability are suitable for use in the sea environment. Modern methods of hydraulic pumps designing and constructing cannot be done without using the appropriate mathematical models of effects and processes occurring in real pump structures. The mathematical model of a process is analytical interpretation of the process with certain assumptions [6]. Any improvements of the pump performances can provide financial and energy savings and by that have a positive impact on the environment [7].

Techno-economical optimization of vibro-diagnostic method implies the definition of such method that fulfils the request for minimal number of research vibration formats needed for precise diagnostic of broad spectre of errors at all types of rotating machines. Finding the 
optimal solution for concrete structure of defined application means the selection of structure parameters to achieve the maximum value of assigned goal function. Value functions that constitute the goal function represent the components used to form the final evaluation. Individual values of goal partial functions are defined with weight factors, which are assigned to individual partial functions depending on the priority of particular functions. Values of goal partial functions are directly dependent on optimization parameters, which are furthermore in conjunction with basic independent variables. All previously mentioned makes the optimization hierarchy chain, which in its integrity represents the universal formulae for finding the optimal solution.

\section{Optimization problem}

Defined goal function in our concrete example is the selection of optimal vibro-diagnostic formats set which provides the maximum possibility of dynamic problem detection, selection and verification, together with economic justification and simplicity of use. However, it is possible to conclude that the existence of dynamic problems is a characteristic for certain types of rotating machines, which could be categorized in particular groups depending on nominal power, speed, type of foundation, etc.

Ship is a complicated object for analysis since vibro diagnostic method has to be adjusted to an influence of rotating pumps on reliability of exploitation system of the whole ship. Therefore weight factor of rotating pumps and influence on safety of ship, as well as on reliability in exploitation, has decisive position. Same pumps (refer structure, power, speed etc.) mounted in fuel supply or lubricating system in main engine unit ( or ballast system) are more important referring to those mounted in auxiliary system. Therefore, ship choice of the diagnostic method (and costs of diagnostics) will be different in both situations.

In vibro diagnostic analysis ISO 13709:2009 standard part 6.9.3 considers centrifugal pump whose vibrations vary with flow, usually being minimum in the vicinity of the best efficiency point flowrate and increasing as flow is increased or decreased. The change in vibration as flow is varied from the best efficiency point flowrate depends upon the pump's energy density, its specific speed and its suction-specific speed. In general, the change in vibration increases with increasing energy density, higher specific speed and higher suction-specific speed.

According to the ISO 10816 standard, all machines are divided into four classes. For each of them references are given for allowed level of vibrations, points for measuring the vibrations, ways of measuring and the selection of measuring parameters.

In ISO 10816 part 7, rotating pumps are determined in the scope of level of vibration permeated for certain class of pumps and in the context of measuring relative and absolute vibrations.

It is possible to carry out further fusion of certain machine classes regarding the possibility of prospective dynamic problem causes, into two general groups according to ISO 10816 :

Group 1 (g1) used in ships, consisting of:

- Class I machines according to ISO 10816-1, small machines - typically electric motors up to $15 \mathrm{~kW}$

- Class II machines according to ISO 10816-1, medium machines - electro motors with power from $15 \mathrm{~kW}$ to $75 \mathrm{~kW}$ without special foundation, rotating machines with special foundation and power up to $300 \mathrm{~kW}$

Group 2 (g2) used in shipbuilding, consisting of:

- Class III machines according to ISO 10816-1, large machines on rigid foundations

- Class IV machines according to ISO 10816-1, large machines on soft foundations

For the selection of adequate format set we started from the request for minimal number of vibro-diagnostic formats which could precisely detect the existence of certain dynamic problem cause in the machine systems. Minimal format set of vibro-diagnostics, which is considered as necessary, should consist of measuring the total vibration levels, spectral analysis and time-domain analysis. Other vibro-diagnostic sets are chosen to include minimal number of vibro-diagnostic formats from the specific format group. The review of chosen vibrodiagnostic sets is shown in Tab. $1[8,10]$.

Table 1 Review of chosen vibro-diagnostic sets

\begin{tabular}{|c|c|c|c|c|c|c|}
\hline SET A & SET B & SET C & SET D & SET E & SET F & SET G \\
\hline Measuring of total vibrations level & \multirow{4}{*}{$\begin{array}{l}\text { HFD } \\
\text { level }\end{array}$} & \multirow{4}{*}{$\begin{array}{c}\text { Envelope } \\
\text { spectral } \\
\text { display }\end{array}$} & \multirow{4}{*}{$\begin{array}{l}\text { Bodeo's } \\
\text { display }\end{array}$} & \multirow{4}{*}{$\begin{array}{c}\text { Cascade } \\
\text { spectral display }\end{array}$} & Smax & \multirow{4}{*}{$\begin{array}{c}\text { Modal form of } \\
\text { oscillation }\end{array}$} \\
\hline Spectral display & & & & & $X-Y$ position & \\
\hline Polar trend display & & & & & & \\
\hline Time-domain analysis & & & & & Oroital dispray & \\
\hline
\end{tabular}

For finding the maximum of established goal function, independently for mentioned machine groups, adequate diagnostic models were considered. Recommended compositions of sets for intended diagnostic models are shown in Tab. 2.

During the research we came to the conclusion that optimal diagnostic model, i.e. optimal vibro-diagnostic format set, could be perceived in totality through four value functions:
- Identification of dynamic problem cause

- Simplicity of use

- Early detection of dynamic problem

- Economical aspect. 


Table 2 Composition of sets - Group 1 (g1) and Group 2 machines (g2)
\begin{tabular}{|l|c|}
\hline \multicolumn{1}{|c|}{ MARKING (g1) } & SET COMPOSITION \\
\hline Model I & $\mathrm{A}$ \\
\hline Model II & $\mathrm{A}+\mathrm{B}$ \\
\hline Model III & $\mathrm{A}+\mathrm{B}+\mathrm{C}$ \\
\hline Model IV & $\mathrm{A}+\mathrm{B}+\mathrm{C}+\mathrm{E}$ \\
\hline Model V & $\mathrm{A}+\mathrm{B}+\mathrm{C}+\mathrm{E}+\mathrm{G}$ \\
\hline \multicolumn{1}{|c|}{ MARKING (g2) } & SET COMPOSITION \\
\hline Model I & $\mathrm{A}$ \\
\hline Model VI & $\mathrm{A}+\mathrm{D}$ \\
\hline Model VII & $\mathrm{A}+\mathrm{D}+\mathrm{E}$ \\
\hline Model VIII & $\mathrm{A}+\mathrm{D}+\mathrm{E}+\mathrm{F}$ \\
\hline Model IX & $\mathrm{A}+\mathrm{C}+\mathrm{D}+\mathrm{E}+\mathrm{F}+\mathrm{G}$ \\
\hline
\end{tabular}

\section{Identification of dynamic problem cause}

Probability of certain dynamic problem happening in real exploitation conditions is taken into consideration during the generation of value functions according to these criteria. Furthermore, each of vibro-diagnostic formats provides a part of information regarding the existence of a given problem, so the probability of problem detection for certain format must also be considered.

By analysing the previous facts we can come to the equation for calculation of value function for certain vibro-diagnostic formats, i.e. vibro-diagnostic format sets, by these criteria $[8 \div 10]$

$V_{\mathrm{D}}=\sum_{\mathrm{Vphenomena}} * V_{\text {Detection }} / 100$

$V_{\mathrm{D}}$ - identification of dynamic problem cause,

$V_{\text {Phenomena }}$ - partial probability of distinct defect occurrence,

$\mathrm{V}_{\text {Detection }}$ - probability of dynamic problem cause detection,

$\Gamma$ - value function by criteria of dynamic problem cause identification

Value function, by these criteria, for some of chosen models (vibro-diagnostic format sets) for machines (group 1 and group 2) is shown in Tab. 3.

Table 3 Value function by criteria of dynamic problem cause identification (for Group 1 and Group 2 machines)*

\begin{tabular}{|l|c||l|c|}
\hline Analyst type (g1) & $\Gamma(\%)$ & Analyst type (g2) & $\Gamma(\%)$ \\
\hline Model I & 80,5 & Model I & 81 \\
\hline Model II & 85,5 & Model VI & 87 \\
\hline Model III & 89 & Model VII & 90 \\
\hline Model IV & 90,5 & Model VIII & 92,3 \\
\hline Model V & 91 & Model IX & 93,7 \\
\hline
\end{tabular}

* Table contains data obtained by scientific research from a scientific research project at the Faculty of Mechanical Engineering Nis, Serbia [1]

\section{Simplicity in derivation and application}

Value function, based on the criteria, simplicity and application, should be formed considering the following parameters, with specific weight coefficient $k_{\mathrm{z}}$ :

- Instruments setting and adjusting $k_{\mathrm{z}}=0,3$

- Dynamic problem cause recognisability, $k_{\mathrm{z}}=0,3$

- Installation of measuring sensors, $k_{\mathrm{z}}=0,2$

- Memorizing and result transmission, $k_{\mathrm{z}}=0,2$.

Simplicity in derivation and use is defined as:
$K=\sum k_{\mathrm{z}} * V_{\text {Parameter }}$

$k_{\mathrm{z}}$ - weight coefficient

$V_{\text {Parameter }}$ - value of specific parameters

$\xi$ - simplicity in derivation and application.

Table 4 Simplicity in derivation and application

\begin{tabular}{|l|c|}
\hline \multicolumn{1}{|c|}{ Analyst type } & $\xi$ \\
\hline Model I & 100 \\
\hline Model II & 100 \\
\hline Model III & 87,5 \\
\hline Model IV & 62,5 \\
\hline Model V & 40 \\
\hline Model VI & 75 \\
\hline Model VII & 52,5 \\
\hline Model VIII & 37,5 \\
\hline Model IX & 12,5 \\
\hline
\end{tabular}

\section{Early detection of dynamic problem causes}

At the formation of value function by these criteria, similarly as criteria number one, probability of certain dynamic problems occurrence is considered in real exploitation conditions, along with probability of early problem detection for chosen specific format sets. By analysing previous facts, it is possible to obtain the equation for calculation of value function for specific vibro-diagnostic format sets.

$V_{\mathrm{D}}=\sum_{\mathrm{VPhenomena}} * V_{\text {Early detection }} / 100$

$V_{\mathrm{D}}$ - value function by criterion of early dynamic problem cause detection

$V_{\text {Phenomena }}$ - partial probability of specific defect occurrence

$V_{\text {Early detection - probability of dynamic problem cause }}$ detection in early phase of appearance

$\Psi$ - value function for machines.

Value function, by these criteria, for some of chosen models (vibro-diagnostic format sets), for machine groups 1 and 2 , is shown in the following table $[8,9,10,11]$.

Table 5 Value function for machines (group 1 and group 2)*

\begin{tabular}{|l|c||l|c|}
\hline \multicolumn{1}{|c|}{ Analyst type (g1) } & $\Psi$ & Analyst type (g2) & $\Psi$ \\
\hline Model I & 37,5 & Model I & 50 \\
\hline Model II & 60 & Model VI & 72 \\
\hline Model III & 62 & Model VII & 81 \\
\hline Model IV & 74 & Model VIII & 88.5 \\
\hline Model V & 76 & Model IX & 90 \\
\hline
\end{tabular}

* Table contains data obtained by scientific research from a scientific research project at the Faculty of mechanical engineering Nis, Serbia [8].

\section{Economical aspect}

At the formation of value function by these criteria, the following parameters will be considered, with estimated weight coefficients:

- $\quad$ Price of instruments, $k_{\mathrm{z}}=0,3$

- $\quad$ Price of program support, $k_{\mathrm{z}}=0,3$

- $\quad$ Maintenance costs, $k_{\mathrm{z}}=0,3$

- Costs of operators training and necessary expert advices, $k_{\mathrm{z}}=0,1$. 
Some of value function parameters could have one of given values: $25,50,75$ or 100 . Specific parameter values for certain models are given in the following table.

Table 6 Value parameters of economical function

\begin{tabular}{|l|c|c|c|c|}
\hline $\begin{array}{c}\text { Analyst } \\
\text { type }\end{array}$ & $\begin{array}{c}\text { Price of } \\
\text { hardware }\end{array}$ & $\begin{array}{c}\text { Maintenance } \\
\text { costs }\end{array}$ & $\begin{array}{c}\text { Training } \\
\text { costs }\end{array}$ & $\begin{array}{c}\text { Price of } \\
\text { software }\end{array}$ \\
\hline Model I & 100 & 100 & 100 & 100 \\
\hline Model II & 75 & 100 & 100 & 75 \\
\hline Model III & 75 & 75 & 75 & 50 \\
\hline Model IV & 75 & 50 & 50 & 25 \\
\hline Model V & 25 & 25 & 25 & 0 \\
\hline Model VI & 100 & 75 & 75 & 75 \\
\hline Model VII & 100 & 50 & 50 & 50 \\
\hline Model VIII & 25 & 0 & 25 & 25 \\
\hline Model IX & 0 & 25 & 25 & 0 \\
\hline
\end{tabular}

Value functions for specific chosen models, are calculated according to estimated criteria, using the following equation:

$E=\sum k_{\mathrm{z}} * V_{\text {Parameter }}$ $k_{\mathrm{z}}$ - coefficient of parameter significance.

Value function for specific models is shown in the following table.

Table 7 Economical aspect of considered analyst models

\begin{tabular}{|l|c|}
\hline \multicolumn{1}{|c|}{ Analyst type } & Economical aspect \\
\hline Model I & 100 \\
\hline Model II & 92,5 \\
\hline Model III & 82,5 \\
\hline Model IV & 65 \\
\hline Model V & 17,5 \\
\hline Model VI & 82,5 \\
\hline Model VII & 65 \\
\hline Model VIII & 42,5 \\
\hline
\end{tabular}

\section{Value of assigned goal function}

Value functions for considered analysts are shown in the following table, regarding the considered machine groups

Table 8 Value functions of considered analyst models for g1 and g2 machines

\begin{tabular}{|c|c|c|c|c|}
\hline \multicolumn{5}{|c|}{ GROUP 1} \\
\hline Analyst type & $\begin{array}{l}\text { Identification of dynamic } \\
\text { problem }\end{array}$ & Simplicity in derivation and use & $\begin{array}{l}\text { Early detection of dynamic } \\
\text { problem }\end{array}$ & Economical aspect \\
\hline Model I & 80,5 & 100 & 37,5 & 100 \\
\hline Model II & 85,5 & 100 & 60 & 92,5 \\
\hline Model III & 89 & 87,5 & 62 & 82,5 \\
\hline Model IV & 90,5 & 62,5 & 74 & 65 \\
\hline Model V & 91 & 40 & 76 & 17,5 \\
\hline \multicolumn{5}{|c|}{ GROUP 2} \\
\hline Analyst type & $\begin{array}{c}\text { Identification of dynamic } \\
\text { problem }\end{array}$ & Simplicity in derivation and use & $\begin{array}{l}\text { Early detection of dynamic } \\
\text { problem }\end{array}$ & Economical aspect \\
\hline Model I & 81 & 100 & 50 & 100 \\
\hline Model VI & 87 & 75 & 72 & 82,5 \\
\hline Model VII & 90 & 52,5 & 81 & 65 \\
\hline Model VIII & 92,3 & 37,5 & 88,5 & 42.5 \\
\hline Model IX & 93,7 & 12,5 & 90 & 10 \\
\hline
\end{tabular}

After the completion of value functions calculation, it is possible to provide the final result about the optimal vibro-diagnostic formats set for considered machine groups. Specific values of significance levels for corresponding value functions as taken as:

- Identification of dynamic problem cause $y=0,5$

- Simplicity in derivation and use $y=0,2$

- Early detection of dynamic problem cause $y=0,2$

- $\quad$ Economical aspect $y=0,2$.

Goal function is formed from already defined value functions, taken with corresponding significance level. So, the value of goal function can be calculated using the following equation:

$\Delta=\sum y_{i} * V_{i}$

$\Delta$ - value of goal function

$V_{i}$ - value of corresponding value function

$y_{i}$ - specific significance level of corresponding value function

Calculated values of goal function for specific models are given in the following table.
Table 9 Value of goal function of considered model for machines (group 1 and group 2)

\begin{tabular}{|l|c||l|c|}
\hline $\begin{array}{c}\text { Analyst type } \\
(\mathrm{g} 1)\end{array}$ & $\begin{array}{c}\text { goal value } \\
(\Delta)\end{array}$ & $\begin{array}{c}\text { Analyst type } \\
(\mathrm{g} 2)\end{array}$ & goal value $(\Delta)$ \\
\hline Model I & 78,75 & Model I & 80,5 \\
\hline Model II & 84,00 & Model VI & 81,2 \\
\hline Model III & 82,65 & Model VII & 78,2 \\
\hline Model IV & 79,05 & Model VIII & 75,6 \\
\hline Model V & 70,45 & Model IX & 67,4 \\
\hline
\end{tabular}

\section{Conclusion}

Examination of vibration phenomenon provides us with the data about the volume of working parameters changes and the intensity of vibrations. On the basis of obtained results we evaluate the safety level for marine rotating pumps and the whole plant. Beside mentioned, in most cases it is necessary to determine the cause of nonstationary occurrences that should be either removed or amortized. Working ranges that should be avoided are determined in many cases. Primary sources of vibrations at rotating pumps are mechanical, hydraulic and electric processes caused by the design, manufacturing technology, working regime and exploitation. 
From previous analyses we can conclude that optimal composition of vibro-diagnostic format sets, which have maximal possibility of dynamic problem cause identification, together with probability of early defect detection and simplicity in derivation and use, considering also the economical aspect, are found in the following models:

- For GROUP 1 (G1) machines - optimal vibrodiagnostic model is Model II. Its program structure includes basic format sets and a HFD levels display.

- For GROUP 2 (G2) machines - optimal vibrodiagnostic model is Model VI. Its program structure includes basic format sets and a Bodeo's display.

This is one way to perform the optimization of vibrodiagnostic models, i.e. chose the optimal analytical models, which in their program structure include represented vibro-diagnostic format sets.

\section{References}

[1] Golub, I. et al. Fault Tree Analysis in the Reliability of Heavy Fuel Oil Supply. // Transactions on maritime science. 2, (2014), pp. 131-136. DOI: 10.7225/toms.v03.n02.004

[2] Bukša, A.; Martinović, D.; Vidaković, M. Analiza kvarova dizelskog motora brodskog porivnog sustava. // Pomorstvo. 23, 2(2009), pp. 391-404.

[3] Bukša, A. et al. Ship Machinery Maintenance Concept Adjustment and Design. // Strojarstvo. 51, 3(2009), pp. 227-238.

[4] Delalić, S. et al. Influence of hybrid pumps rotor construction on cavitation occurrence and pumps efficiency. // Tehnički vjesnik. 14, 3,4(2007), pp. 47-51.

[5] Micev, G.; Mrakovčić, T. Analysis of the ship piping installation effect on the mounting and operation of pumps. // Scientific Journal of Maritime Research. 27, 1(2013), pp. 21-37.

[6] Petrović, R. et al. Influence of air content entrained in fluid of a vane pump with double effect operating parameters. // Tehnički vjesnik. 21, 2(2014), pp. 401-407.

[7] Mihalić, T. et al. Improving centrifugal pump by adding vortex rotor. // Tehnički vjesnik. 20, 2(2013), pp. 305-309.

[8] Milovančević, M.; Milenković, D.; Troha, S. The optimization of the vibrodiagnostic method applied on turbo machines. // Transactions of FAMENA XXXIII-3 (2009), pp. 63-71

[9] Milovančević, M. et al. Embedded condition monitoring of power transmission of a pellet mill. // Transactions of FAMENA XXXIIII-2 (2010), pp. 71-79.

[10] Vračar, Lj.; Milovančević, M.; Karanikić, P. Application of smart mobile phones in vibration monitoring. // Facta Universitatis, series: Mechanical Engineering. 13, 2(2015), pp. 143-153.

[11] Stefanović-Marinović, J.; Milovančević, M. The Optimization Possibilities at the Planetary Gear Trains. // Journal of Mechanics Engineering and Automation (JMEA). 2, (2012) pp. 396-402.

\section{Authors' addresses}

Miloš Milovančević, PhD

Faculty of Mechanical Engineering, University of Nis Aleksandra Medvedeva 14, 18000 Nis, Serbia E-mail: milovancevic@masfak.ni.ac.rs

\section{Edvard Tijan, PhD}

University of Rijeka, Faculty of Maritime Studies Studentska 2, 51000 Rijeka, Croatia E-mail: etijan@pfri.hr

\section{Petra Karanikić, PhD}

University of Rijeka, Department of Biotechnology Radmile Matejčić 10, 51000 Rijeka, Croatia E-mail: pkaranikic@biotech.uniri.hr 